\title{
Banishing the Fear of Public Speaking COMMUNICATION CORNER
}

\author{
by Philip Yaffe
}

\section{Editor's Introduction}

Each "Communication Corner" essay is self-contained; however, they build on each other. For best results, before reading this essay and doing the exercise, go to the first essay "How an Ugly Duckling Became a Swan," then read each succeeding essay.

In this installment, Philip Yaffe explores how speak to a crowd. 


\title{
Banishing the Fear of Public Speaking
}

\author{
COMMUNICATION CORNER
}

\section{by Philip Yaffe}

At the beginning of the Communication Corner series, I said we would be exploring both good expository (non-fiction) writing and public speaking. There is still more to be said about writing; however, I think we have come far enough that it is time to turn our attention to public speaking. Moreover, much of what is still left to be said about writing directly applies to public speaking, because they are flip sides of the same coin. If you write well, you will probably speak well; if you write poorly, you will probably speak poorly.

Writing and speaking are intimately related and should be considered together, rather than as distinct disciplines. So let's get started at treating them together, as their integrated natures rightly demand.

A survey published in the 1970 s showed Americans feared public speaking more than death, catastrophic illness, or anything else. Similar results have been found in other countries as well.

At first glance this seems to be an astounding revelation; however, it needs to be put into context. Although we know that illness, and certainly death, may be lurking somewhere in the future, the necessity of speaking in public is an everyday menace. This doesn't necessarily mean public speaking in the sense of giving a formal speech. It could be something as simple as participating in a committee meeting, making a presentation in a training program, taking an oral examination, etc.

Everyone knows speaking in public will not result in painful or permanent impairment. But since it is so much more immediate than death and disease, public speaking seems to be an everpresent threat.

I can well sympathize with this irrational trepidation because I used to be an extreme case. As an adolescent I would tend to avoid participating in groups, and even going out with groups of friends, for fear I would say something ridiculous or humiliating. I certainly would never stand up in class at school and voice my opinion on anything.

This dread of public speaking lasted well into adulthood. Then one day, it all changed. And yes, it did take only one day, or thereabouts. Here's what happened. 
Early in my career, I was a marketing communication consultant for a large pharmaceutical company. One of my missions was to conduct what amounted to roundtable discussions with specialist doctors at international medical congresses. I had never done anything like this before and was terrified at the prospect. I have a science degree from UCLA (University of California at Los Angeles), but I never considered myself in the same class as leading anesthesiologists, cardiologists, dermatologists, pediatricians, and the like. So I was terrified of saying something stupid.

My first assignment was at a gastroenterology congress. Each participant in the roundtable had to fill in a card with their vital statistics (name, city, country, hospital or private practice, etc.) so that I could introduce them to each other. One participant had neglected to fill in his specialty; the line was blank. For reasons I will never understand, I blurted out, "Oh, I see we have someone here who doesn't want to tell us what he does. I can only assume that he is a proctologist who is ashamed to admit it."

When I realized what I had said, my blood ran cold. I expected the ground to open up and swallow me whole. Instead, I first heard one doctor chuckle, then the rest of them joined in with hearty laughter, including the "proctologist." What I thought had been stupid and unpardonable, they found funny.

I was relieved, but not convinced. Shortly afterward I had to do similar roundtables at a psychiatry congress. Again for reasons I will never understand, I said, "Do you know what happens when you put two psychiatrists together? You get three opinions and four diagnoses. And all of them wrong." Now that really was stupid. Once again, I expected the ground to open up and swallow me. Once again, I was greeted with hearty laughter.

And it continued to happen. Each time I did a roundtable with specialist doctors whom I considered to be way out of my league they seemed to accept me as a colleague and a friend.

This was a revelation. I wasn't going out of my way to be clever or cute, yet people seemed to enjoy what I was saying. Even when they didn't actually laugh, I could see smiles on their faces. They also reacted positively to questions I might ask and the comments I might make on their answers.

But why? When I put my mind to it, it didn't take too long to figure it out.

A speaker and an audience are natural allies. Even if it's not their free choice, they have made the effort to come to where you are to hear what you have to say, so they want to make the best of it. They want you to succeed: Because if you do, they do.

For at least the first few minutes, therefore, they are likely to be totally focused on your presentation, hoping that it will be interesting and entertaining. In other words, they will give you the benefit of the doubt, until you prove them wrong. 
Make good use of this initial goodwill, because it is fragile and can rapidly dissipate. On the other hand, if you get off to a good start, even if you slip up later on, your audience is likely to want to stay with you.

Here are a few tips to help you overcome nervousness and ensure that you use the audience's initial goodwill to best advantage.

\section{Be yourself}

We have all seen speakers whose presentations we admire. It is only natural to think, "If only I could do it the way they do it, I would be a great success." You can learn from other speakers; however, the worst thing you can do is to try to imitate them.

Chances are that you admire them because when they speak, they project themselves, not someone else. Listeners sense honesty and passion, and appreciate it. Your style is your style; your thoughts are your thoughts. They are unique. No one else can use them as well as you can, just as you can't use other people's style and thoughts as well as they can.

Be yourself, and enjoy it!

\section{Have an excess of information}

The more information you have when preparing your presentation, the better you can choose what to use and what not to use. However, information you choose to leave out is not useless. It is proof that you know more about your subject than what you are going to say.

If you put everything you have into the presentation, of course you will be nervous, because you will fear that the listeners will find what you are saying to be weak and shallow. By contrast, knowing that you have chosen the real pearls of your subject to present to your listeners will make nervousness disappear.

\section{Memorize the introduction and conclusion}

It is generally a bad idea either to read or memorize your presentation because this tends to drain it of personality and spontaneity. Nevertheless, you are well advised to memorize both the introduction and the conclusion word for word.

- Introduction. To capitalize on the listeners' initial high interest in your presentation, you need a clear, concise, confident statement of what you are going to talk about. The introduction should be carefully crafted and memorized word for word in order to leave nothing to chance.

Knowing exactly what you are going to say at the beginning helps you get comfortably up to cruising speed, so any initial nervousness rapidly disappears. 
- Conclusion. The conclusion is perhaps the single most important part of your presentation because last said = longest remembered. Like the introduction, the conclusion should be carefully crafted and memorized word for word in order to leave nothing to chance.

Knowing exactly what you are going to say in the conclusion acts like a beacon. If nervousness returns in the middle of your presentation, focusing your mind on what you will say at the end helps you get back on track. Nervousness disappears.

This idea works even for informal public speaking, such as conducting roundtables. Knowing exactly what you are going to say at the beginning and at the end provides invaluable assistance in getting you through the unprepared middle.

\section{Minimize mistakes}

Here is an idea that should boost your confidence. When you are speaking, it is very difficult to make a mistake. Or at least it is very difficult to make a mistake that listeners will notice, unless you tell them about it.

Speaking is ephemeral. Your words are in the air, and then they are gone. Even listeners who think you said something wrong are likely to give you the benefit of the doubt and forget about it the moment you pass on to something else.

If you make a mistake (and everyone does), do one of the following:

- Minor mistake. If the mistake is minor, don't draw attention to it. We all have slips of the tongue, especially when we are nervous. The more minor mistakes you admit to, the more nervous you will become, thus increasing the likelihood that you will make even more mistakes.

- Major mistake. If the mistake is major, i.e. something that could seriously mislead your listeners, correct it. Avoid being overly apologetic. You want to correct the mistake, not dramatize it. Simply say that you think you have made a misstatement that could be important, put it right, then move on.

Commenting on the 1970s survey, comedian once Jerry Seinfeld observed: "According to most studies, people's number one fear is public speaking. Death is number two. Does that sound right? This means that for the average person, if you go to a funeral, you're better off in the casket than doing the eulogy."

Famed author and lecturer Mark Twain once observed: "There are two kinds of speaker, those who are nervous and those who are liars."

However, the most insightful comment on the subject comes from Franklin Delano Roosevelt, America's iconic 32nd president. Although aimed at a totally different problem, FDR confidently declared: "The only thing we have to fear . . . is fear itself." 


\section{HOMEWORK: Retrospective to Communication Corner No. 8}

In the previous installment, you were shown an article that was published in an internal company newsletter. It was an excellent example of why such newsletters are generally poorly read. It clearly did not follow Yaffe's Law: If you give people what they want first, they are likely to accept anything else you want them to have. If you give them what you want first, chances are they won't accept anything at all.

You were asked to rewrite the article, including the headline according to Yaffe's Law, using all the approaches and techniques you have learned in previous Communication Corner installments, e.g. clear, concise, dense, inverted pyramid, $5 \mathrm{Ws} \& \mathrm{H}$, etc.

Here is my rewrite of the article. As usual, bear in mind that there is more than one way of writing something well. So if your version differs from mine, don't worry, just as long as it's palpably better than the original.

\section{"Fffervescent Russian Fconomy Looks to BubbleChem to Keep Its Foam under Control"}

At a time when the Russian economy seems to be quickly recovering from the recent financial crisis, Russians are rapidly reverting to purchase of fully automatic washing machines, which require use of detergent formulas for full-cycle foam control. BubbleChem's patented powdered Encapsulated AntiFoam (EAF) product is a leading contender to keep all this new Russian foam well within limits.

"Because production of low-foaming detergents is sharply increasing, significant new sales of EAF in Russia can be expected in the very near future," said Hans Styverson, BubbleChem's Global Marketing Leader for Household Cleaning Products.

How did this important new opportunity come about?

Earlier in the year, firm contacts were made with Mr. Ivan Watsolvski (General Director) and Mrs. Natalia Krova (Deputy Science Director) of Gisnova, one of Russia's leading laundry detergent manufacturers, when BubbleChem participated in the Russian detergents conference. This is where EAF was presented to the Russian detergent industry for the first time. It attracted considerable interest and attention. BubbleChem's product has since been tested by many potential customers and is currently undergoing its first qualifications.

From December 13-17, Ruble \&e Kopek, our Russian distribution team, led a high-level delegation, including members of Gisnova, to visit BubbleChem. The visit was organized to BubbleChem's two Belgian facilities to show these influential Russian detergent officials our advanced technologies. 
Impressed by what she saw, Mrs. Krova said, "BubbleChem has great facilities and products. We are very excited by the prospect of bringing BubbleChem's expertise and innovation to the Russian detergents market."

"For us to succeed in this potentially vast market, we need a Russian voice of authority. Gisnova has built up a tremendous amount of scientific experience in detergent technology and has an outstanding reputation," explained Hans Styverson. "We are very honored that they want to work with us," he added.

\section{Analysis}

The key question most people consciously or subconsciously ask themselves when invited to read a document is: "What's in it for me?" In other words, "What benefit will I get by reading this?"

Unlike the original article, this revised version immediately offers readers information about the near- and medium-term prospects of BubbleChem, which in turn helps them evaluate their near- and medium-term prospects of keeping their jobs and perhaps looking forward to rising salaries. It's hard to resist reading something so intimately related to one's personal and economic well-being.

Of course, all of this information was in the original article, but it was so far down the text that most readers probably would never have gotten to it. Good expository writing presents key information upfront; it doesn't challenge readers to find it on their own.

\section{CURRENT HOMEWORK}

There is no current homework other than the pleasure of reading and learning from Abraham Lincoln's Gettysburg Address, both as writing and as speaking. Here is the address.

Abraham Lincoln, American's iconic 16th president (1861-1865), was not generally known as a great orator. Much of his wisdom-and he was a very wise man-was expressed in plain, simple language. However, he is frequently credited with penning he did pen lines that have echoed down the ages. For example:

- You can fool all of the people some of the time, and some of the people all of the time, but you cannot fool all of the people all of the time.

- It is better to remain silent and be thought a fool than to open one's mouth and remove all doubt.

- A house divided against itself cannot stand. 
However, his most famous words are assuredly: "Four score and seven years ago our fathers brought forth on this continent a new nation, conceived in liberty and dedicated to the proposition that all men are created equal."

Equally famous are: "And that government of the people, by the people, for the people, shall not perish from the earth."

These are the opening and closing lines of The Gettysburg Address. This brief oration was delivered by President Lincoln in 1863 at Gettysburg, Pennsylvania, to mark a pivotal victory in the American Civil War. Known to every American schoolchild, it is universally recognized as one of the greatest speeches of all time.

What makes it so great? To my mind, it is because it incorporates all the fundamental principles, and many of the tips and techniques I hope to impart in this series of Communication Corner essays.

Quite likely Lincoln was not consciously thinking about these principles and techniques as he wrote. Few good writers and speakers ever do, because somehow they have assimilated them without ever actually having been taught them. Why? Many books and courses on writing and speaking focus on the superficialities without ever getting down to the bedrock of what these essential disciplines are truly all about.

Throughout the writing of these Communication Corner essays, Lincoln's miniature masterpiece has been my constant inspiration. In only 272 carefully crafted words, Lincoln says more than most people could say in several thousand.

Here is "The Gettysburg Address" as Lincoln wrote it. It is followed by my analysis of it. If you don't already appreciate what a masterpiece the address is, by the time you have finished reading this section, I hope and expect that you will.

\section{"The Gettysburg Address"}

(November 19, 1863)

Four score and seven years ago our fathers brought forth on this continent a new nation, conceived in liberty and dedicated to the proposition that all men are created equal.

Now we are engaged in a great civil war, testing whether that nation-or any nation so conceived and so dedicated-can long endure. We are met on a great battlefield of that war. We have come to dedicate a portion of that field as a final resting place for those who here gave their lives that that nation might live. It is altogether fitting and proper that we should do this.

But in a larger sense, we cannot dedicate, we cannot consecrate, we cannot hallow this ground. The brave men, living and dead, who struggled here have consecrated it far above our poor power to add or detract. 
The world will little note, nor long remember, what we say here, but it can never forget what they did here. It is for us the living, rather, to be dedicated here to the unfinished work which they who fought here have thus far so nobly advanced.

It is rather for us to be here dedicated to the great task remaining before us. That from these honored dead we take increased devotion to that cause for which they gave the last full measure of devotion. That we here highly resolve that these dead shall not have died in vain. That this nation, under God, shall have a new birth of freedom. And that government of the people, by the people, for the people, shall not perish from the earth.

\section{Comments}

Abraham Lincoln was not reputed to be a good speaker. Among other things, he had a somewhat weak and irritating voice. So the power of "The Gettysburg Address" was mainly in the words, not the delivery.

Some reports suggest he scribbled it on the back of an envelope just before arriving in Gettysburg. This is probably a myth, but the feeling the speech engenders makes the story seem plausible.

I think most of us would readily agree it fulfills the three critical criteria of good writing.

1. It is clear. It says what it has to say with no extraneous information to get in the way of its message.

2. It is concise, i.e. as long as necessary and as short as possible.

3. It may be less obvious that it is dense, i.e. that is contains precise information logically linked. However, bear in mind that "precise information" does not necessarily mean names, dates, quantities, places, etc. It can also mean concepts.

The address clearly conveys concepts about the nature of the nation on whose behalf the war was being fought (dedicated to the proposition that all men are created equal, that they are endowed). And the over-arching objectives of the war (that government of the people, by the people, for the people shall not perish from the earth).

Now let's examine some of the technical aspects of the address sentence-by-sentence to see how Lincoln so masterfully achieved his objective. There are only nine of them.

But first a caveat.

As any teacher knows, saying something once is tantamount to not saying it at all. People may recognize an idea the first time it is presented, but they almost never assimilate it and make it their own until it is repeated. Nevertheless, in expository (non-fiction) writing, repetition seems 
to be a no-no. The purpose of expository writing is generally to inform or instruct; yet young writers are often enjoined to avoid repetition at all costs.

I became aware of this bizarre and detrimental phenomenon by living in Europe (Belgium since 1974) and learning other languages (fluent French, working knowledge of Dutch, German, and Spanish). Everyone I know who writes documents in these languages will do just about anything to avoid repeating a word. It seems that when they were in school, they were told that if they repeated a word, their hands would be cut off. Verbal variety was a prime virtue, repetition a prime sin.

Intentionally used, repetition improves rather than degrades writing. The key word is "intentionally." As in teaching (expository writing and speaking are a kind of teaching), saying something once seldom gets the point across. The solution, we are told, is to say it several times, but in different ways. However, constantly changing vocabulary for the sake of variety more often than not leads to confusion rather than clarity.

In short, skillfully adherence to the same terminology can advance your argument; indiscriminately mixing terminology can hobble it.

\section{Analysis of "The Gettysburg Address"}

\section{Sentence 1}

Four score and seven years ago, our fathers brought forth on this continent a new nation, conceived in liberty and dedicated to the proposition that all men are created equal.

The language of the mid-19th century was somewhat more florid than what we use today. But it appears that Mr. Lincoln purposely employed such phraseology to give his first words almost biblical importance. He could have said, "Eighty-seven years ago, our country was founded based on the idea that all men are created equal." Hardly the same thing, is it?

\section{Sentence 2}

Now we are engaged in a great civil war, testing whether that nation - or any nation so conceived and so dedicated-can long endure.

The sentence begins, "Now we are engaged in a great civil war...." This is very plain, almost banal, language suggesting war is a mean and dirty business. The rest of the sentence then reverts to more sophisticated language to ennoble the purposes of the war. Note repetition of the words "conceived" and "dedicated" from the first sentence. This heightens the impact of the statement, which would have been seriously diminished if Mr. Lincoln had believed it mandatory to avoid such repetition.

\section{Sentence 3}


We are met on a great battlefield of that war.

This is another banal statement. It could easily have been combined with the fourth sentence by saying "battlefield of that war in order to dedicate...." But notice how much stronger it is standing by itself. This is an excellent example of the "separation" technique.

\section{Sentence 4}

We have come to dedicate a portion of that field as a final resting place for those who here gave their lives that that nation might live.

This sentence once again contains a repetition, or at least a near repetition: “...who here gave their lives that that nation might live." These two words complement each other and reinforce Mr. Lincoln's thought. He could have chosen "survive," "overcome," "prosper," or a dozen other alternatives to avoid this near repetition. I hope you will agree that none of them would have been anywhere near as effective.

\section{Sentence 5}

It is altogether fitting and proper that we should do this.

Yet another banal statement, providing dramatic contrast between the sophisticated statement that precedes it and the sophisticated statement that follows it.

\section{Sentence 6}

But in a larger sense, we cannot dedicate, we cannot consecrate, we cannot hallow this ground.

Note the near repetition created by the words "dedicate," "consecrate," "hallow." This is almost tautological, as it was meant to be in order to emphasize the thought.

\section{Sentence 7}

The brave men, living and dead, who struggled here, have consecrated it far above our poor power to add or detract.

Note the repetition of the word "consecrated." The tautology continues, further emphasizing the thought of the previous sentence.

\section{Sentence 8}

The world will little note, nor long remember, what we say here, but it can never forget what they did here. 
Oh, what an understatement! Mr. Lincoln probably truly believed this, but he was wrong. Virtually every American schoolchild learns these words by heart, and the speech is known and recognized as a masterpiece well beyond the borders of the United States.

\section{Sentence 9}

It is rather for us to be here dedicated to the great task remaining before us. That from these honored dead we take increased devotion to that cause for which they gave the last full measure of devotion. That we here highly resolve that these dead shall not have died in vain. That this nation, under God, shall have a new birth of freedom. And that government of the people, by the people, for the people, shall not perish from the earth.

This sentence, although divided by periods in the written form, is in fact a single, unified thought. The four fragments starting with "That" could have been linked to the main clause by commas or semicolons. However, separating them by periods gives each one greater emphasis, like "oral bullet points."

The sentence powerfully expresses Mr. Lincoln's convictions about the purposes of the war he passionately hated yet found himself constrained to pursue. The last "bullet point" has almost become America's national motto: "That government of the people, by the people, for the people, shall not perish from the Earth."

Shakespeare's famous Marc Antony soliloquy on the assassination of Julius Caesar, another beautiful piece of writing, also gives a feeling of "premeditated spontaneity." Let's examine just the first few lines.

\section{Sentence 1}

Friends, Romans, countrymen, lend me your ears. I come to bury Caesar, not to praise him.

This is the perfect introduction to a speech, i.e. "tell them what you are going to tell them." It is also very simple language, suggesting that the speech will be neither polemical nor great oratory. It will be a heart-felt statement of bereavement.

\section{Sentence 2}

The evil that men do lives after them; the good is oft interred with their bones.

Once again very simple language, but something has already begun to change. Note the excellent use of contrast to stimulate and maintain interest. "I come to bury Caesar, not to praise him" in the first sentence, and "evil" and "good" and "lives" and "interred" in the second.

\section{Sentence 3}




\section{So let it be with Caesar.}

Brutus has already denounced Caesar as a tyrant who had to be killed for the general good. Antony suggests otherwise, raising expectations in the crowd, only apparently to definitively dash them, thus heightening their interest. This is an excellent example of the "separation" technique, i.e. breaking a sentence for dramatic impact.

Shakespeare could have written: "The evil that men do lives after them; the good is oft interred with their bones and so let it be with Caesar."

Now compare this with how it was actually written: "The evil that men do lives after them; the good is oft interred with their bones. So let it be with Caesar."

The difference is remarkable.

\section{Sentence 4}

The noble Brutus hath told you Caesar was ambitious. If it were so, it was a grievous fault, and grievously hath Caesar answer'd it.

Once again, Antony reverses position. "If it were so ..." clearly indicates that he disagrees with Brutus. We are back to the polemic.

Also note the power in the near repetition of "grievous" and "grievously". The statement would have been significantly weaker had Shakespeare felt compelled to avoid such repetition-a grievous fault of many less accomplished writers.

\section{Sentence 5}

Here, under leave of Brutus and the rest-for Brutus is an honorable man; so are they all, all honorable men-come I to speak in Caesar's funeral.

Here comes the masterstroke: "for Brutus is an honorable man; so are they all, all honorable men." By now there can be little doubt that Antony is using the word "honorable" ironically; he is in fact suggesting Brutus and his co-conspirators are liars and hypocrites.

\section{Sentence 6}

He was my friend, faithful and just to me. But Brutus says he was ambitious, and Brutus is an honorable man. 
Here again Shakespeare works his magic by repeating both "ambitious" and "honorable." This heightens the impact of the statement, which would have been seriously diminished by substitutes. For example: "But Brutus says he was tyrannical and Brutus is worthy of our trust." The same thought, but nowhere near the same power.

\section{Sentence 7}

He hath brought many captives home to Rome, whose ransoms did the general coffers fill. Did this in Caesar seem ambitious?

Again repetition of "ambitious." Also, Antony asks a question rather than making a statement. The listeners are enjoined to answer the question for themselves, and of course the answer is "no," just as Antony wants.

\section{Sentence 8}

When that the poor have cried, Caesar hath wept. Ambition should be made of sterner stuff.

Note the use of "cried" and "wept." Not only did Caesar empathize with the poor; he felt their pain even more than they did themselves. Also note the near repetition, "ambition" rather than "ambitious."

\section{Sentence 9}

Yet Brutus says he was ambitious, and Brutus is an honorable man.

"Ambitious" and "honorable." These two words now resound like a drumbeat. Antony has effectively transformed their meanings. "Ambitious" now means "compassionate" and "honorable" now means "ignoble." This drumbeat continues throughout the text.

I suggest you now get a copy of the soliloquy and read it read as Shakespeare wrote it, without interruption, keeping in mind the above analysis. Also note the rhythm. Not only is the text clear, it flows almost like a poem without actually being one.

Rhythm in expository writing is seldom mentioned because when it flows so easily it is seldom noticed. However, it is there if you look for it. And you should, because it is one of the subtle things that convert an ordinary text into a great one. 


\section{About the Author}

Philip Yaffe was born in Boston, Massachusetts, in 1942 and grew up in Los Angeles, where he graduated from the University of California with a degree in mathematics and physics. In his senior year, he was also editor-in-chief of the Daily Bruin, UCLA's daily student newspaper. He has more than 40 years of experience in journalism and international marketing communication. At various points in his career, he has been a teacher of journalism, a reporter/feature writer with The Wall Street Journal, an account executive with a major international press relations agency, European marketing communication director with two major international companies, and a founding partner of a specialized marketing communication agency in Brussels, Belgium, where he has lived since 1974. He is the author of more than 20 books, which can be found easily in Amazon Kindle.

DOI: $10.1145 / 3281453$ 